\title{
Surface Characterization by X-Ray Photoelectron Spectroscopy of Polyethersulfone Hollow Fiber Membranes Modified with Surface Modifying Macromolecules
}

\author{
N. Bolong ${ }^{1,2 \& 3^{*}}$, A. F. Ismail ${ }^{2}$, M. R. Salim ${ }^{3}$, D. Rana ${ }^{4}$ \& T. Matsuura ${ }^{5}$ \\ ${ }^{1}$ Advanced Membrane Research Centre, Faculty Of Chemical \& Natural Resources Engineering, Universiti \\ Teknologi Malaysia (UTM), 81310 Skudai, Johor Malaysia \\ ${ }^{2}$ Dept. of Environmental Engineering, Faculty of Civil Engineering, Universiti Teknologi Malaysia (UTM), 81310 \\ Skudai, Johor Malaysia \\ ${ }^{3}$ Civil Engineering Programme, School of Engineering \& IT, Universiti Malaysia Sabah (UMS), \\ 88999 Kota Kinabalu, Sabah, Malaysia \\ ${ }^{4} \& 5$ Industrial Membrane Research Laboratory, Dept. of Chemical and Biological Engineering, University of \\ Ottawa, 161 Louis Pasteur St, Ottawa, Ont. K1N 6N5, Canada
}

\begin{abstract}
Novel charged-surface modifying macromolecules (CSMMs) were synthesized and incorporated into polyethersulfone (PES) hollow fiber membranes for water separation application. The macromolecules were synthesized with diisocynate, polypropylene oxide and poly (ethylene glycol)-hydroxybenzene sulfonate (PEG-HBS). In this study, the surface of polyethersulfone hollow fiber membranes prepared by the phase inversion method was modified using $1 \mathrm{wt} . \%$ of SMM and $22 \mathrm{wt} . \%$ PES concentration in the polymer casting solution. The effect of CSMM on PES hollow fiber membrane modification was investigated. Elemental analysis shows enrichment of oxygen and sulfone on the modified PES membrane bulk properties. In addition, the glass transition temperature confirms the miscibility of the cSMM in PES. Important relations between surface characteristics due to SMM modification with the PES membrane for water separation performance with respect to XPS characterization also highlighted.
\end{abstract}

Keywords: Surface modifying macromolecule; polyethersulfone hollow fiber membranes; surface modification, $\mathrm{x}$-ray photoelectron spectroscopy

\subsection{INTRODUCTION}

Nanofiltration technology in water application has been widely studied due to its ability to remove hardness, organics and particulate contaminants and to reduce ionic strength of a solution (Hilal et al., 2004) and to reject organic solutes more effectively than ultrafiltration (Schafer, 2001). Most of the commercially available nanofiltration membranes are composite polyamide membranes prepared by interfacial polymerization (Kesting,

\footnotetext{
* Corresponding to: N. Bolong (email: nurmin@ums.edu.my)
}

1985). However, the drawbacks of polyamide membranes is their susceptibility to free chlorine and alkaline which causes degradation of the amide group. In this work, nanofiltration is developed by a new approach based on polyethersulfone (PES). PES is a polymer closely related to polysulfone (PS) and has a high glass transition temperature of $230^{\circ} \mathrm{C}$. It has advantages of good membrane forming properties (an important criteria in hollow fiber formation), high mechanical and chemical stability, commercial availability and relatively low cost. PES has the best characteristic of polymers such as segmental flexibility and processability and capability to be constructed in module forms 
(Mahajan, 2000). However, PES polymers being slightly hydrophobic, are not suitable for RO or NF applications without further modifications by suitable chemical reactions like sulfonation (Dey, 2004).

One of the key factors to control membrane properties and structures for achieving the required performance is the alteration of the membrane surface. To modify membrane surface, various methods have been developed such as cross-linking, plasma treatment, grafting technique etc. (Du and Zhou, 2003; Castilho et al., 2002). However, it would be desirable to modify the membrane surface by a simple single-step casting procedure, which is enabled by blending surface modifying macromelocules (SMMs) into the polymeric casting solution, as employed in this work. In this method, only a small quantity of active additive is required (Khayet et al., 2003). The active additive, namely surface modifying macromolecule (SMM), has the ability to migrate preferentially toward a polymer-air interface at membrane surface due to thermodynamic incompability between the host polymer and SMM (Suk et al., 2006). In particular, blending of SMMs that carry a charged functional group (CSMM) can increase the surface charge density of the membrane.

The objective of this work is to evaluate the PES-cSMM miscibility, thus evaluating the feasibility of spinning cSMM blended hollow fibers, to confirm the presence of CSMM in at the surface of the hollow fiber and to study the surface characteristics of the hollow fiber. In order to understand the surface properties towards its separation performance, $\mathrm{x}$-ray photoelectron spectroscopy (XPS) is used to analyze the surface chemical structure of the hollow fibers.

\subsection{EXPERIMENTAC METHODS}

\subsection{CSMM Synthesis and Hollow Fiber Membrane Fabrication}

Materials used in this study are as follows; polyethersulfone (PES, Radel A-300, Amoco Chemicals, Germany); N-methyl-2-pyrrolidinone (NMP, anhydrous 99.5\%), N,N-dimethylacetamide (DMAc, 99+\%), N,N-dimethylacetamide (DMAc, $99+\%)$, methylene bis-p-phenyl diisocyanate (MDI), Hydroxybenzenesulfonic acid, sodium salt dehydrate (HBS, 98\%), Poly (ethylene glycol) (PEG, $400 \mathrm{Da}$ ) and Diethylene glycol(DEG) all supplied from Sigma-Aldrich, Inc., USA.

The charged-SMM (cSMM) used for dope formulation in this work were laboratory synthesized by the method(Bolong et al., 2009, Mohd Norddin et al., 2008), and have the structures shown in Figure 1.

Based on the soft-segment of the polyurethane prepolymer, namely polyethylene glycol (PEG), and the end capping group, namely hydroxybenzene sulfonate sodium salt (HBS). The utilized cSMM in this work is called poly (ethylene glycol)hydroxybenzene sulfonate (PEGHBS) according to their soft segment and end-capped.

The cSMM was synthesized using a two-step solution polymerization method. The initial step involved the reaction of methylene bis-p-phenyl diisocynate (MDI) with poly (ethylene glycol) (PEG) in solvent $\mathrm{N}, \mathrm{N}$-dimethylacetamide (DMAc). This mixture formed a urethane prepolymer solution. The prepolymer is a blockedsegment of urethane oligomer, poly $(4,4$ 'diphenylenemethylene propyleneurethane) having both ends capped with isocyanate. The second step is the end-capping step by the addition of

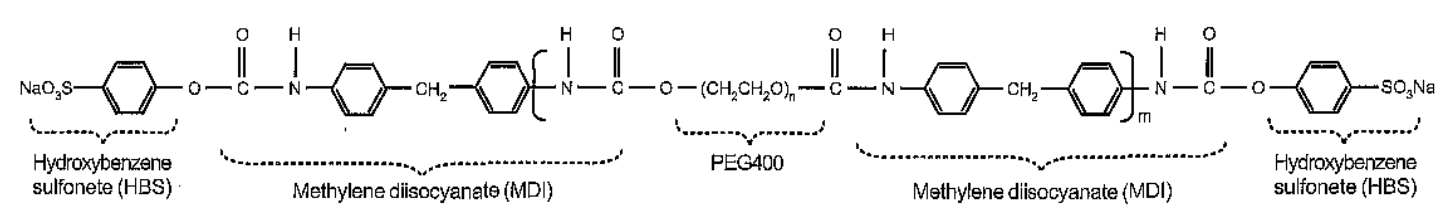

Figure 1 Chemical structures of poly (ethylene glycol)-4,4' methylene bis (phenyl isocyannatehydroxybenzene sulfonate 


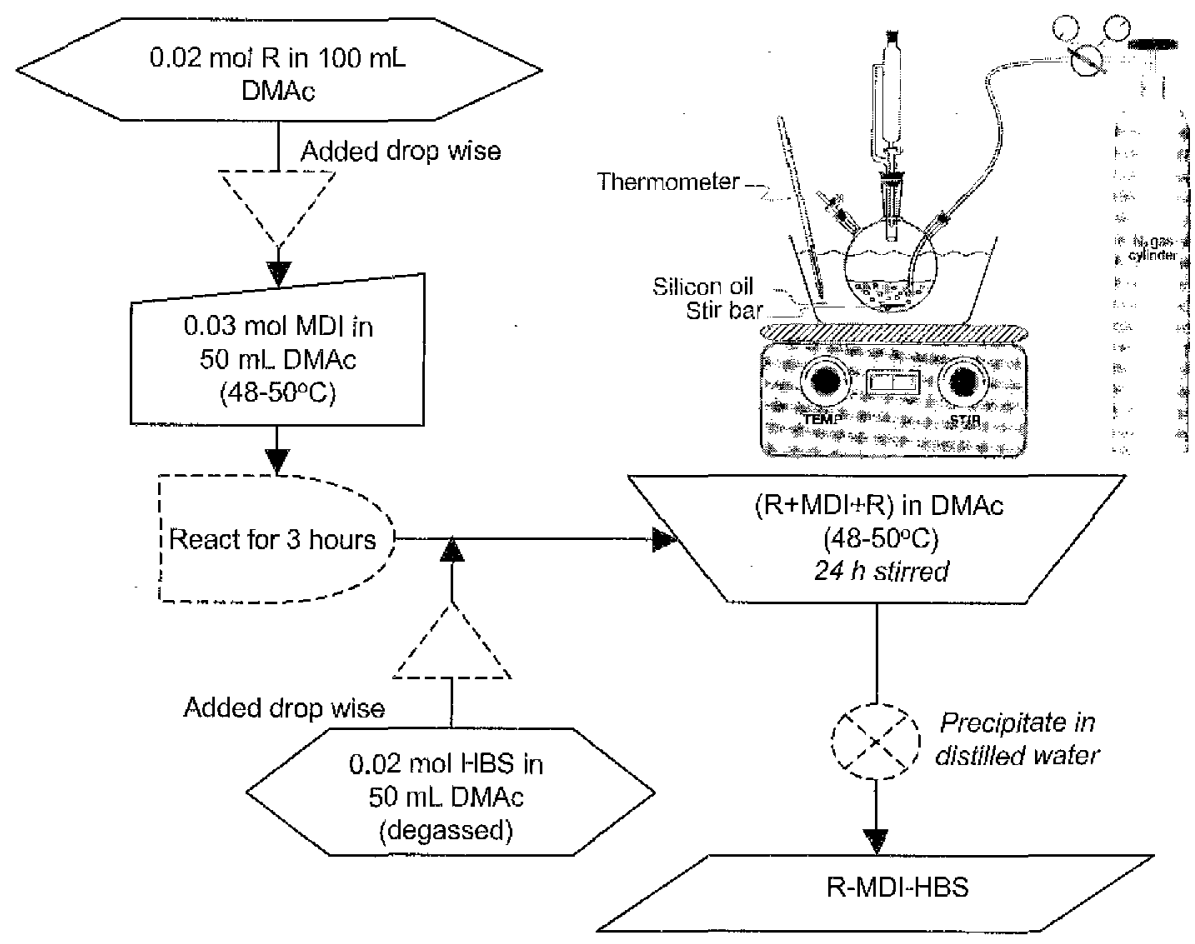

Figure 2 Synthesis procedure of charged surface modifying macromolecule (CSMM) Poly (ethylene glycol)-4,4' methylene bis(phenyl isocyannate- Hydroxy-benzene sulfonate (PEG-MDI-HBS) in reaction vessel

hydroxybenzene sulfonic acid (HBS). This prepolymerisation and end-capping process were performed in a controlled atmosphere of purified nitrogen in a reaction vessel. To ensure the elimination of the effects of moisture, all the glasswares were dried at $100^{\circ} \mathrm{C}$ and DMAc was degassed prior to use. The detailed procedure was outlined in Figure 2.

After the resulting solution of cSMM was left under stirring for $24 \mathrm{~h}$ at $48-50^{\circ} \mathrm{C}$, the CSMM was added dropwise into distilled water under vigorous stirring to precipitate $\mathrm{CSMM}$. The precipitated cSMM was slightly elastic but it was possible to cut it into small pieces. Those pieces were further washed three times and kept immersed in distilled water for 24 hrs under stirring to leach out residual solvent. They were then placed in an aluminum foil and dried in an air circulation oven at $50^{\circ} \mathrm{C}$ for 5 days, by which a constant weight of approximately $10 \mathrm{~g}$ was obtained. The CSMM was stored in a glass bottle wrapped with aluminum foil, which was then placed in a desiccator.
Hollow fiber membranes were fabricated in the laboratory using a simple phase inversion technique. The hollow fiber membranes were spun at $5 \mathrm{~cm}$ air gap using water as coagulant both in the coagulation tank and in the bore fluid. Prior to spinning, a spinning dope consisting of PES, water (Deionised), cSMM and $N$-methyl-2-pyrrolidinone was prepared by the procedure described elsewhere (Bolong et al., 2008) to produce an asymmetric hollow fiber membrane.

\subsection{Elemental Analysis and Differential Scanning Calorimetry (DSC)}

The bulk elemental composition (carbon, hydrogen and sulfur) for the modified and unmodified hollow fiber membranes was determined by elemental analyzer (Perkin Elmer PE2400 Series II, USA).

The miscibility of PES-cSMM blend was evaluated by measuring the glass transition temperature $(\mathrm{Tg})$ of the polymers using a 
differential scanning calorimeter (Mettler Toledo DSC 822e). Samples were cut into small pieces, weighed to $6 \pm 0.5 \mathrm{mg}$ and placed in a pre-weighed aluminum crucible. Then, the sample was heated from 25 to $250^{\circ} \mathrm{C}$ with a heating rate of $20^{\circ} \mathrm{C}$ $\min ^{-1}$. Tg of the sample was determined as the midpoint temperature of the transition region in the heating cycle.

\subsection{X-ray Photoelectron Spectroscopy (XPS)}

X-ray photoelectron spectroscopy (XPS) or also known as electron spectroscopy for chemical analysis (ESCA) is particularly well suited for examining the skin layer of a membrane, since it probes only at resolution depth of $-10 \mathrm{~nm}$ into the membrane surface. XPS analyses were carried out with Axis-165 ultra (Kratos Analytical, Shimadzu, Japan) using $\mathrm{MgK} \alpha$ exciting radiation $(\mathrm{hv}=1253.6 \mathrm{eV})$. The excitation source was run at $15 \mathrm{kV}$ and $10 \mathrm{~mA}$. To compensate for surface charging effects, all binding energies were referenced to the $\mathrm{C} 1 \mathrm{~s}$ neutral carbon peak at 284.5 $\mathrm{eV}$.

Surface elemental stoichiometries were determined from the sensitivity-factor-corrected peak area ratios, and the software XPSpeak 4.1 was used to fit the XPS spectral peaks. Prior to XPS tests, hollow fiber membranes were rinsed in distilled water and then dried in an vacuum oven at a temperature of $30^{\circ} \mathrm{C}$ for 8 hours to remove moisture or water, which would affect the XPS sampling environment during chamber evacuation, and consequently ensure sufficient vacuum on the measurement system. Hollow fiber membrane sample was compactly arranged and directly pressed to a self-supported $(10 \times 10 \mathrm{~mm})$ disk and mounted on a sample holder before being transferred into the analyzer chamber.

\subsection{RESULTS AND DISCUSSION}

\subsection{SMM and Fabricated Hollow Fiber Membranes Properties}

The hollow fibers were spun by the dry-wet phase inversion technique using dopes of three different compositions as shown in Table 1. All the fabricated hollow fiber membranes were dissolved using N-methyl-2-pyrrolidinone (NMP) and only SMM $1 \%$ weight was needed to cover the membrane surfaces (Rana et al., 2006) and also to avoid massive changes to the base material.

A well known method of thermal characterization is differential scanning calorimetry (DSC), in which the thermal property is monitored as enthalpy change. A miscible blend exhibits a single Tg whereas an immiscible blend shows multiple Tgs (Kapantaidakis et al., 1996). The midpoint $\mathrm{Tg}$, given as the temperature at which half of the total change in the specific heat capacity occurs, is summarized in Table 1.

All membranes exhibited a single $\mathrm{Tg}$, which implies the homogenous blend of CSMM (PEGHBS) with PES. The Tg's of all the hollow fibers of multi-components are less than the hollow fiber of the single pure PES component. It seems that the addition of CSMM reduces Tg considerably but for the formulation that includes water, $\mathrm{Tg}$ partially comes back to the nearly original value of pure PES. Compositional variation of $\mathrm{Tg}$ is mainly governed both by the interaction between the components and the change in chain flexibility with the compositional change (Kim and Jang, 2002).

The bulk elemental analysis of the fabricated hollow fibers shows only a slight change in $\mathrm{Tg}$ when cSMM is added (Table 1). The blends of PEGHBS show an increase of in sulfur content with occurrence of nitrogen which is attributed to the amide group in the PEGHBS.

Table 1 DSC scan midpoint temperature and bulk atomic percentage of membranes

\begin{tabular}{|c|c|c|c|c|c|c|}
\hline \multirow{2}{*}{$\begin{array}{l}\text { Membrane } \\
\text { composition } \\
(w \mathrm{t} \%)\end{array}$} & \multicolumn{2}{|c|}{$\operatorname{Tg}\left({ }^{\circ} \mathrm{C}\right)$} & \multicolumn{4}{|c|}{$\begin{array}{r}\text { Bulk Elemental } \\
\text { (Atomic ratio) }\end{array}$} \\
\hline & & $\mathbf{C}$ & $\mathbf{H}$ & $\mathbf{N}$ & $\mathbf{S}$ & 0 \\
\hline PES (22) & 231 & 3.29 & 7.32 & 0.00 & 0.15 & 2.9 \\
\hline $\begin{array}{l}\text { PES-PEGHBS } \\
(22 / 1)\end{array}$ & 208 & 3.89 & 6.53 & 0.08 & 0.22 & 2.4 \\
\hline $\begin{array}{l}\text { PES-PEGHBS } \\
\text { Water }(22 / 1 / 5)\end{array}$ & 228 & 3.50 & 6.94 & 0.07 & 0.19 & 2.7 \\
\hline
\end{tabular}




\subsection{X-ray Photoelectron Spectroscopy (XPS) Analysis}

The surface compositions of the modified and unmodified hollow fiber membranes were determined using XPS. X-ray resolution data was collected at incident $\mathrm{X}$-ray angle $(\theta)$ of $90^{\circ}$. The $\theta$ angle is measured relative to the horizontal plane of the sample surface. It represent the top $<10 \mathrm{~nm}$ of the membrane surface. The survey of the XPS spectrum confirmed the presence of the desired elements in the hollow fiber samples as shown in Figure 3. Wide scan of samples displayed the peaks arising from ionization of core electron of $\mathrm{C}, \mathrm{N}, \mathrm{O}$ and $\mathrm{S}$. Weak peak appearing at $402 \mathrm{eV}$ for modified PES notation for N1s observed due to amide N-H of PEGHBS, indicating surlace modification but the peak is too small for further analyses and may not be the main concern of the modification study. On the other hand, $\mathrm{C} 1 \mathrm{~s}, \mathrm{O} 1 \mathrm{~s}$, S2p and S2s peak appeared at 280-290 ev, 530$540 \mathrm{ev}, 170-180$ and $240-250 \mathrm{ev}$ respectively.
To further investigate the effect of PEGHBS blending, further analysis was conducted on the states of $\mathrm{C}$ and $\mathrm{O}$ atoms. The analysis was limited to the PES (without blending) and PES-PEGHBSWater membranes. This is because the PESPEGHBS-Water was found to exhibit better performance than the PES-PEGHBS membrane. For example, pure water permeation was $11.1 \mathrm{~L} / \mathrm{m}^{2}$.h. Bar and $4.5 \mathrm{~L} / \mathrm{m}^{2}$.h. Bar, respectively, for PES-PEGHBS-Water and PES-PEGHBS membrane (Bolong et al., 2009).

In order to reveal the states of the atoms of the modified (PES-PEGHBS-Water) and the unmodified (PES) membrane, the high resolution XPS spectra of C1s and O1s were analyzed by peak fitting based on Gaussian functions. In Figure 4 and 5 respectively, the XPS spectra of the C1s and $\mathrm{O} 1 \mathrm{~s}$ region are shown in high resolution for both the modified PES-PEGHBS-Water and unmodified PES membranes.

Figure 4 shows the $\mathrm{C} 1 \mathrm{~s}$ spectra. It is difficult to make complete analysis of the $\mathrm{C} 1 \mathrm{~s}$ spectra due to

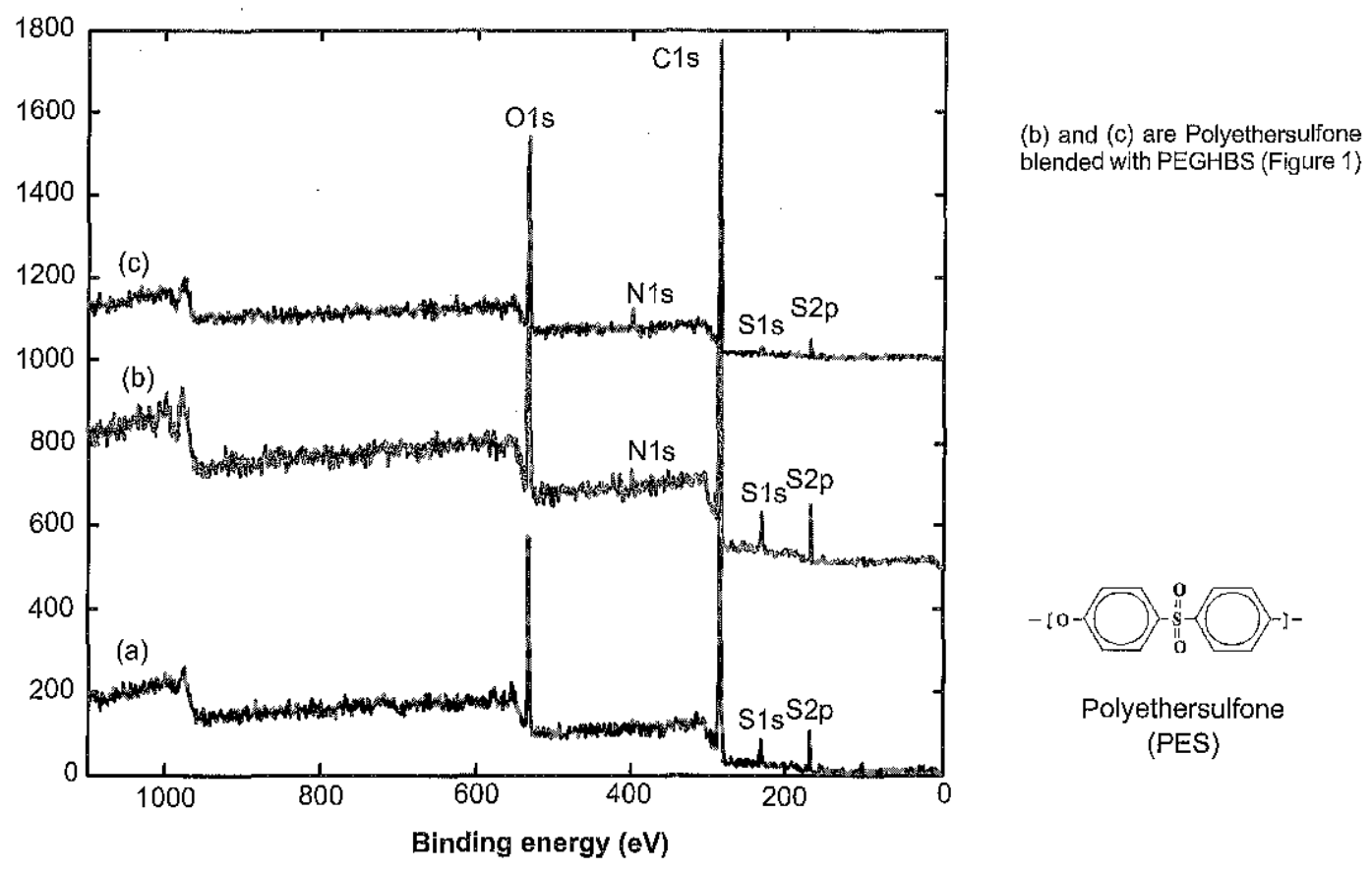

Figure 3 XPS Wide scan (0-1100 eV) of hollow fiber samples (a) PES unmodified, (b)PES/PEGHBS and (c)PES/Water/PEGHBS 
many different chemical states of carbon atoms. Hence, the C1s spectrum were deconvoluted into 3 main peaks for unmodified PES whereas 4 main peaks for modified PES. This is because the observed spectrum for modified PES has broader left shoulder compared to unmodified PES indicating of surface modification due to PEGHBS blends. The main peak at the binding energy of $284.4 \mathrm{ev}$ can be assigned to the phenyl carbon (Folkesson et al., 1998) that exists in the backbone of both membranes. It is reasonable to note that C1s spectra shows a broad line width structures, since it contains contributions of several carbons in different chemical sites. Yet, the correspond binding energy reported by other study (Wavhal et al., 2002) reveals similar spectra for the unmodified PES membrane studied in this work. As shown in Figure 4, both PES membranes confirm the occurrence of C-S and C-O at respective binding energy of $285.3 \mathrm{eV}$ and 286.2 $\mathrm{eV}$. The carbon atom bonded to the sulfur atom $\mathrm{C}$ $S$ is present in both types of membranes, however due to modification of PEGHBS, stronger peak

(a) PES without PEGHBS

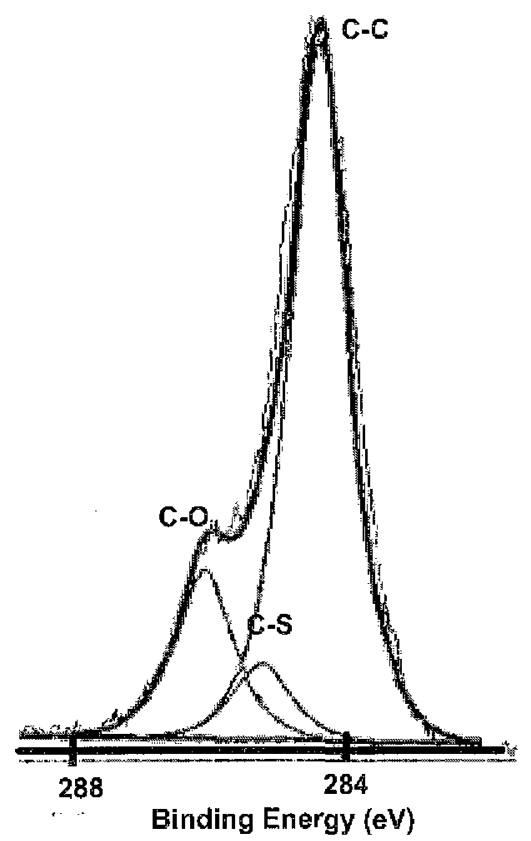

was observed, and that caused a significant revolution at left shoulder of $\mathrm{C} 1 \mathrm{~s}$ spectrum.

Another prominent peak at $288 \mathrm{eV}$ that attributed to $\mathrm{C}=\mathrm{O}$ configuration (Rats et al., 1995) reveals presence of PEGHBS via the MDI components, in the modified PES-PEGHBS-Water membrane.

The $01 \mathrm{~s}$ spectrum of the membranes was deconvoluted by peals fittings as depicted in Figure 5 (a) and (b). Since both membranes base polymer is PES, the peak at $530.7 \mathrm{eV}$ that assigned for the oxygen present in the sulfonic acid group ( $\mathrm{C}-\mathrm{S}=\mathrm{O})$ (Nasef et al., 2002) and at binding energy of 531.7 $\mathrm{eV}$ that is contributed from $\mathrm{O}=\mathrm{S}=\mathrm{O}$ (Wavhal et al., 2002) was depicted. By comparison of the O1s spectrum of modified PES membrane with that of original or unmodified membrane, it is found that the C-O-C peak $(532.9 \mathrm{eV})$ has impose left shoulder severely compared to modified PES. The reason might due to the overlapping peak of $\mathrm{C}=\mathrm{O}$ (at $531.5 \mathrm{eV}$ ) with $\mathrm{O}=\mathrm{S}=\mathrm{O}$ implicate the migration of oxygen atom at mernbrane surface due to cSMM (i.e PEGHBs) added.

(b) PES with PEGHBS

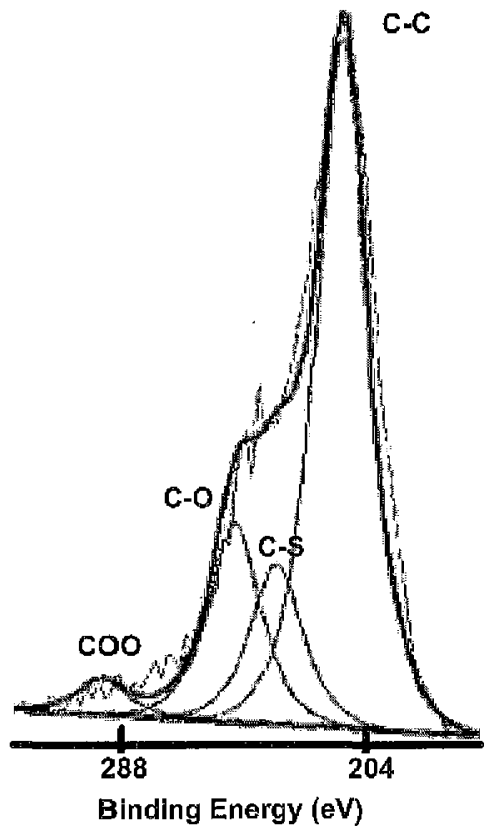

Figure 4 The XPS spectrum of C1s region for the (a) PES unmodified and (b) PES modified with PEGHBS 
(a) PES without PEGHBS

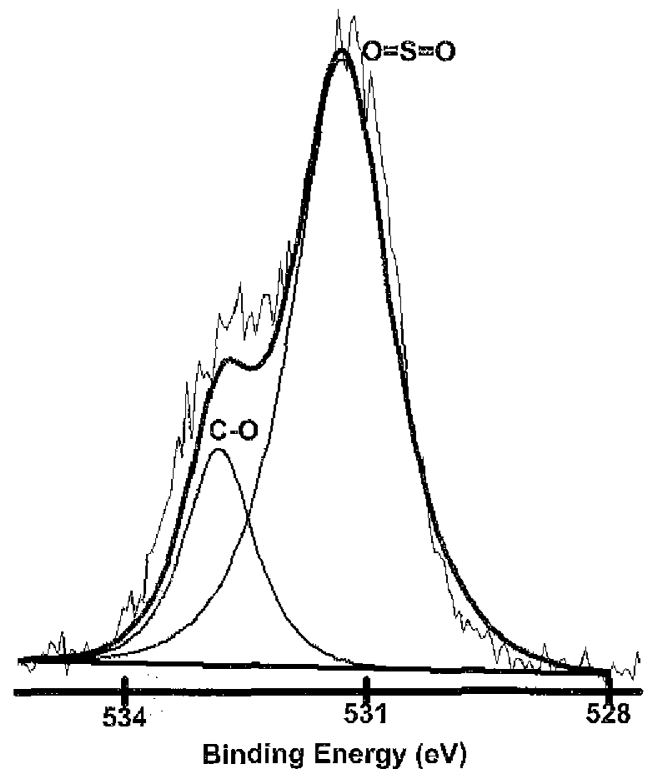

Figure 5 The XPS spectrum of O1s region for the PEGHBS

\subsection{CONCLUSIONS}

The following conclusions can be drawn from the experimental results.

(1) Flemental analysis showed the increase in $N$ and $S$ content in the cSMM (PEGHBS) blended membranes. This is an evidence for the presence of PEGHBS in the membranes surface and hence confirms the move-up towards membrane surface.

(2) According to DSC analysis, only a single Tgs were obtained for the cSMM blended membranes, this is the verification for the perfect miscibility of PEGHBS in PES.

(3) The left shoulder of the main $\mathrm{C} 1 \mathrm{~s}$ peak was enhanced by the peak corresponding to atom carbon binding with sulfur. The right shoulder of the main O1s peak was enhanced by the peak corresponding to sulfonic acid $(\mathrm{S}=\mathrm{O})$. All of the XPS data analysis suggests the modification of PEGHBS at PES membrane surface, which successfully migrated at membrane surface and indeed present in the modified PES-PEGHBSWater membrane. (b) PES with PEGHBS

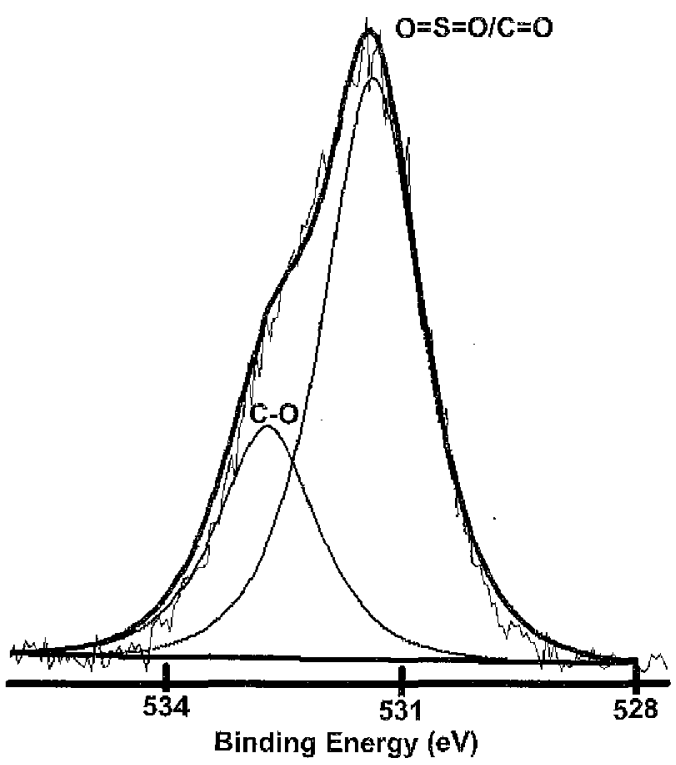

(a) PES unmodified and (b) PES modified with ACKNOWLEDGEMENT

This research has been financially supported by Ministry of Higher Education, Malaysia (MOHE) and Universiti Malaysia Sabah (UMS). The author wishes to thank Prof. Zeng Hua Chun from the Department of Chemical and Biomolecular Engineering, National University of Singapore (NUS), Singapore; who gave us the possibility to undertake visiting scholar progamme at NUS and access to the elemental analysis and XPS facility.

\section{REFERENCES}

[1] Abdureyim, A., K. K. Okudaira, Y. Harada, S. Masuda, M. Aoki, K. Seki, Eisuke Ito and N. Ueno. 2001. Characterization of 4Mercatohydrocynnamic Acid Selfassembled Film on $\mathrm{Au}(111)$ by means of X-ray Photoelectron Spectroscopy. J. of Electron Spectroscopy and Related Phenomena. 114-116: 371-374.

[2] Bolong, N., A. F. Ismail, M. R. Salim, D. Rana and T. Matsuura. 2009. Development and 
Characterization of Novel Charged Surface Modification Macromolecule to Polyethersulfone Hollow Fiber Membrane with Polyvinylpyrrolidone and Water. J. Membr. Sci. doi: 10.1016/j.memsci.2009.01.008.

[3] Bolong, N., A. F. Ismail, M. R. Salim, D. Rana and T. Matsuura. 2008. Influence of Surface Modifying Macromolecules (SMMs) on Polyethersulfone Hollow Fiber Membranes for Water Separations. Presented on $6^{\text {th }}$ Regional Symposium on Membrane Sci. \& Tech. 2008, 13-15 August Phulket Thailand.

[4] Castilho, L. R., W. D. Deckwer and F. B. Anspach. 2002. Influence of Matrix Activation and Polymer Coating on the Purification of Human IgG with Protein A Affinity Membranes. J. Membr. Sci. 172: 269.

[5] Dey, T. K., R. C. Bindal, M. S. Hamra and B. M. Misra. 2004. Dependence of Performance of Poly(Sulfone Co-Amide) Membranes on Compositional Variation of Casting Solution and Coagulation Media Development of Reverse Osmosis and Nanofiltration Membranes. Separation Science \& Technology. 39: 581-601.

[6] Du, R. and J. Zhao. 2003. Positively Charged Composite Nanofiltration Membrane Prepared by Poly (N,N-dimethylaminoethyl methacrylate)/polysulfone. J. Appl. Polym. Sci. 91: 2721.

[7] Folkesson, B., P. Sundberg and R. Larsson. 1988. On the Core Electron Binding Energy of Carbon and the Effective Charge of the Carbon Atom. Journal of Electron Spectroscopy and Related Phenomena, 46: 19-29.

[8] Franks, F., 1988. Water Science Reviews 3: Water Dynamics. Cambridge University Press. UK.

[9] Hilal N., H. Al-Zoubi, N. A. Darwish, A. W. Mohammad and M. Abu Arabi, 2004. A Comprehensive Review of Nanofiltration Membranes: Treatment, Pretreatment, Modeling and Atomic Force Microscopy. Desalination. 170: 281.

[10] Hollinger, G., G. Marest, H. Jaffrezic, J. Tousset and N. Moncoffre. 1985. Temperature Influence during Nitrogen Implantation into Steel. Nuclear Instruments and Methods in Physics Research B7/8. 177-183.

[11] Kapantaidakis, G. C., S. P. Kaldis, X. S. Dabou and G. P. Sakellaropoulos. 1996. Gas Permeation through PSF-PI Miscible Blend Membranes. J. Membr. Sci. 110: 239.

[12] Kesting, R.E. 1985. Synthetic Polymeric Membranes. New York: Wiley.

[13] Khayet, M., D. E. Suk, R. M. Narbaitz, J. P. Santerre and T. Matsuura. 2003. Study on Surface Modification by Surface-modifying Macromolecules and its Applications in Membrane-separation Processes. J. Appl. Polym. Sci. 89: 2902-2916.

[14] Kim, J. H. and J. Jang. 2002. Thickness and Composition Dependence of the Glass Transition Temperature in Thin Homogeneous Polymer Blend Films. Macromolecules. 35: 311.

[15] Mahajan, R. 2000. Formation, Characterization and Modeling of Mixed Matrix Membrane Materials, Ph.D. Dissertation, The University of Texas at Austin.

[16] Mohd Norddin, M. N. A., A. F. Ismail, D. Rana, T. Matsurura and S. Tabe. 2008. The Effect of Blending Sulfonated Poly(ether ether ketone) with Various Charged Surface Modifying Macromolecules on Proton Exchange Membrane Performance. J. Membr. Sci. In Press. doi:10.1016/j.memsci. 2008.12.009.

[17] Moulder, J. F., W. F Stickle, P. E. Sobol and K. D. Bomben. 1995. Handbook of X Ray Photoelectron Spectroscopy: A Reference Book of Standard Spectra for Identification and Interpretation of Xps Data. Physical Electronic Publishers. Perkin Elmer Corp. USA.

[18] Mustin, C. Ph. De Donato, R. Benoit and R. Erre. 1993. Spatial Distribution of Iron and Sulphure Species on the Surface of Pyrite. Applied Surface Science. 68: 147158.

[19] Nasef, M. M. and H. Saidi. 2002. Postmortem Analysis of Radiation Grafted Fuel Cell Membrane using X-ray Photoelectron Spectroscopy. I. of New Mat. for Electrochemical Sys. 5: 183-189. 
[20] Poleunis, C. L., T. Weng, M. Sclavons, P. Bertrand, P. Franquinet, R. Legras and V. Carlier. 1995. Sizing Removal and Functionalization of Carbon Fiber Surface Studied by Combined TOF SIMS and XPS. Journal Adhesion Sci. Technol. 9. 7: 859871.

[21] Rana, D., T. Matsuura, R. M. Narbaitz and C. Feng. 2005. Development and Characterization of Novel Hydrophilic Surface Modifying Macromolecule for Polymeric Membranes. J. Membr. Sci. 249: 103.

[22] Rats, J. D., L. Sevely, R,Vandenbulcke, R. Benoit, R. Erre, V. Herbin and V. Serin. 1995. Characterization of Diamond Films Deposited on Titanium and its Alloys. Thin Solid Films. 270: 177-183.

[23] Schafer, A. I. 2001. Natural Organics Removal Using Membranes: Principles, Performance and Cost. Technomic Pulishing co. Inc, USA
[24] Suk, D. E., T. Matsuura, H. B. Park and Y. M. Lee. 2006. Synthesis of a New Type of Surface Modifying Macromolecules (nSMM) and Characterization and Testing of nSMM Blended Membranes for Membrane Distillation. J. Membr. Sci. 277: 177.

[25] Thompson, A. C and D. Vaughn. 2001. X-ray Data Booklet, US Dept. of Energy (DEAC03-765F00098).

[26] Wagner, C. D., W. M. Riggs, L. E. Davis, J. F. Moulder and G. E. Mullenberg. 1979. Handbook of X-ray Photoelectron Spectroscopy. Perkin-Elmer Corp., Eden Prairie, MN, USA.

[27] Watts, J. F and J. Wolstenholme. 2003. An Introduction to Surface Analysis by XPS and AES. John Wiley \& Sons, USA.

[28] Wavhal, D. S and E. R Fisher. 2002. Hydrophilic Modification of Polyethersulfone Membranes by Low Temperature Plasma-induced Graft Polymerization. J. of Membrane Sci. 209: 255-269. 